ARTICLE

\title{
Hedgehog-BMP signalling establishes dorsoventral patterning in lateral plate mesoderm to trigger gonadogenesis in chicken embryos
}

\author{
Takashi Yoshino ${ }^{1, \dagger}$, Hidetaka Murai ${ }^{2} \&$ Daisuke Saito ${ }^{2}$
}

The gonad appears in the early embryo after several events: cells at the lateral plate mesoderm (LPM) undergo ingression, begin gonadal differentiation and then retain primordial germ cells (PGCs). Here we show that in the chicken embryo, these events are triggered on the basis of dorsoventral patterning at the medial LPM. Gonadal progenitor cells (GPCs) at the ventromedial LPM initiate gonadogenesis by undergoing ingression, whereas mesonephric capsule progenitor cells (MCPCs) at the dorsomedial LPM do not. These contrasting behaviours are caused by Hedgehog signalling, which is activated in GPCs but not in MCPCs. Inhibiting Hedgehog signalling prevents GPCs from forming gonadal structures and collecting PGCs. When activated by Hedgehog signalling, MCPCs form an ectopic gonad. This Hedgehog signalling is mediated by BMP4. These findings provide insight into embryonic patterning and gonadal initiation in the chicken embryo.

\footnotetext{
${ }^{1}$ Department of Zoology, Graduate School of Science, Kyoto University, Kitashirakawa, Sakyo-ku, Kyoto 606-8502, Japan. ${ }^{2}$ Frontier Research Institute for Interdisciplinary Sciences (FRIS), Tohoku University, Aoba-ku, Sendai 980-8578, Japan. † Present address: Department of Stem Cell Biology and Medicine, Faculty of Medical Science, Kyushu University, Maidashi, Higashi-ku, Fukuoka 812-8582, Japan. Correspondence and requests for materials should be addressed to T.Y. (email: yoshino1@hgs.med.kyushu-u.ac.jp) or to D.S. (email: daisuke@m.tohoku.ac.jp).
} 
$\mathrm{n}$ animals, the gonads (testis and ovary) are essential for differentiation and maintenance of germ cells, which are required to create the progeny ${ }^{1,2}$. In the testis, somatic Sertoli cells support spermatogenesis through intimate interaction with germ cells ${ }^{1}$. Likewise, in the ovary, the oocyte develops through bidirectional signal exchanges with neighbouring somatic granulosa cells ${ }^{2}$. The testis and ovary secrete sex hormones to differentiate and maintain male and female characteristics, including the internal sex duct and other sexually dimorphic features $^{3-5}$. Consequently, failure of gonadogenesis leads to infertility and disorders of sex differentiation ${ }^{6,7}$.

In vertebrates, gonadogenesis starts with the formation of sexually indifferent gonads, which emerge as genital ridges bilateral to the mesentery ${ }^{8,9}$. At early stages, the genital ridges do not exhibit any structural sexual dimorphisms, and maintain the capacity to differentiate into both testis and ovary. Subsequently, the bipotential gonad develops into either a testis or an ovary. The molecular mechanisms underlying sex determination (and subsequent sex differentiation of the gonad) have been investigated extensively in mice ${ }^{3,10,11}$. By contrast, the molecular mechanisms underlying the early stages of gonadal cell differentiation remain to be elucidated.

Bipotential gonads arise from a particular part of the coelomic epithelia $^{12}$, which originate from the lateral plate mesoderm (LPM) in vertebrates ${ }^{13}$. The epithelia of the LPM undergo ingression to initiate genital ridge formation ${ }^{14,15}$. These cells start gonadal differentiation by expressing transcription factors, such as Gata4, Lhx9, Wt1 and Nr5a1 in mouse ${ }^{16-18}$. At nearly the same time, primordial germ cells (PGCs), which emerge in the extraembryonic region, migrate and localize to the genital ridge $^{19,20}$ in all vertebrates. Accordingly, multiple processes must occur in parallel to accurately form the early stage of the gonad, including formation of the sexually bipotential genital ridge and acquisition of the capability to attract and retain PGCs. However, it remains unclear how these processes are triggered and orchestrated at the correct part of the vertebrate LPM.

Organogenesis is triggered based on early embryonic patterning. Hedgehog and bone morphogenetic protein (BMP) signals determine embryonic pattern formation and regulate various cellular behaviours, including migration and differentiation, in developing embryos ${ }^{21-24}$. In particular, Sonic hedgehog (SHH) and BMP4 play pivotal roles in the development of the LPM. In chicken embryo, LPM is formed based on mediolateral patterning of mesoderm, which is regulated by BMP4 (ref. 25). By contrast, in mouse and chicken embryo, gut mesenchymal cells derived from splanchnic mesoderm (ventral LPM) undergo orderly differentiation along the radial axis, established by $\mathrm{SHH}^{26,27}$. However, it remains unknown what kind of embryonic patterning is necessary for gonadogenesis, and how this embryonic patterning regulates the initiation of gonadogenesis in vertebrates.

In this study, we used in ovo electroporation to precisely localize the gonadal progenitor cells (GPCs) in a particular region of the LPM of day 2 chicken embryos (E2.0). Moreover, we found that Hedgehog and BMP4 signalling play crucial roles in the localization of GPCs by establishing a dorsoventral axis in the medial LPM, followed by the onset of gonadogenesis, in chicken embryo. Our results elucidate the molecular mechanisms that trigger gonad formation.

\section{Results}

Ventromedial LPM cells initiate gonadogenesis at E2.0. It is generally accepted that coelomic epithelial cells of the LPM undergo ingression to form the gonadal primordium ${ }^{14,15}$. In chicken embryos, such events should occur from E2.0 to E2.7. However, it remains unclear what subset of coelomic epithelial cells gives rise to the gonad primordium, as well as when these cells start migrating. To address these questions, we traced the lineage of LPM epithelial cells in E2.0 chicken embryos by labelling the cells with DiI (Fig. 1a,f, $n=4$; Fig. 1k). The ventromedial aspect of the labelled cells began to migrate soon after DiI injection (Fig. 1b,c,g,h, $n=5$; Fig. 1l,m), and obvious thickening was observed at the ventromedial aspect at E3.0 (Fig. 1d,i, $n=5$; Fig. 1n). These cells differentiated into gonadal cells, as revealed by the expression of its marker GATA4 at E4.5 (Fig. 1e,j, $n=4$; Fig. 1o). These observations indicate that the cells at the ventromedial aspect of LPM are determined as the GPCs as early as E2.0 (Supplementary Fig. 1). This result is consistent with the idea that thickening of a particular region of the LPM in the E3.0 embryo is the first sign of gonadogenesis in the chicken ${ }^{28}$.

At E2.0, the ventromedial LPM cells formed an epithelial structure with a laminin-1-positive basement membrane and an atypical protein kinase C (PKC)-positive apical surface (Supplementary Fig. 2). These cells partially lost epithelial integrity at E3.0; the apical surface was maintained, but laminin-1 accumulated discontinuously (Supplementary Fig. 2). This degradation of epithelial integrity may be related to ingression of GPCs. The cells in the dorsomedial LPM covering the mesonephros (MCPCs; mesonephric capsule progenitor cells), which we previously termed Neph-CE ${ }^{29}$, were behaviourally distinct from GPCs at the ventral side. Unlike GPCs, the MCPCs did not undergo ingression, but remained as epithelia to form mesonephric capsule (Fig. 1, $n=4$; Supplementary Fig. 1) as we previously showed ${ }^{29}$. Subsequently, PGCs were attracted by the GPC-derived gonadal cells, but not by the MCPCs (Supplementary Fig. 3, $n=5$ ).

Hedgehog signalling is activated in GPCs but not in MCPCs. On the basis of the observations described above, we assumed that the mechanisms that caused the differences between GPCs and MCPCs were crucial for triggering gonadogenesis in GPCs. $\mathrm{SHH}$ induces cell differentiation and migration in various contexts, including embryonic development and cancer metastasis ${ }^{22,30}$. $S H H$ is expressed in endoderm adjacent to the GPCs, and the site of $\mathrm{SHH}$ expression is more distant from the MCPCs in both mouse and chicken embryos ${ }^{31,32}$; therefore, we assumed that the higher SHH concentration in GPCs relative to MCPCs is responsible for the differences in Hedgehog signalling activities and responses in GPCs and MCPCs.

To test this idea, we investigated the expression of a $\mathrm{SHH}$ downstream gene, PATCHED, in GPCs and MCPCs in E2.0 chicken embryos ${ }^{33,34}$. As reported previously, we detected $\mathrm{SHH}$ mRNA in the endoderm at E2.0, when GPCs begin to form gonadal primordium by undergoing ingression (Fig. $2 \mathrm{a}-\mathrm{c}, \mathrm{g}-\mathrm{i})^{31}$. Meanwhile, mRNA expression of PATCHED grew stronger in the GPCs. By contrast, expression of PATCHED was absent from the MCPCs (Fig. 2d-i).

$\mathrm{SHH}$ was expressed not only in the endoderm but also in axial structures (notochord and floor plate; Fig. 2a-c,g-i). However, even when the axial structures were removed, PATCHED expression was maintained in the GPCs (Supplementary Fig. 4, $n=4)$. Furthermore, IHH (Indian Hedgehog), the other Hedgehog ligand in chicken embryos ${ }^{35}$, was not expressed in cells surrounding the GPCs (Supplementary Fig. 5). These results indicate that Hedgehog signalling is activated in the GPCs but not in the MCPCs of E2.0 chicken embryos, and that this differential activation pattern is most likely established by $\mathrm{SHH}$ secreted from the endoderm.

Hedgehog signalling is required for GPCs to form gonad. Next, we examined how differential Hedgehog signalling activity 
induces differential behaviours of GPCs and MCPCs. First, we inhibited Hedgehog signalling to investigate whether GPCs required the signal to form gonadal primordium. Because impairment of Hedgehog signalling throughout the body causes embryonic lethality before the formation of gonadal primordium $^{32}$, we blocked Hedgehog signalling in a spatiotemporally controlled manner. We performed regionspecific gene manipulation by a modification of our previously established method for electroporation of genes into MCPCs ${ }^{29}$. Specifically, we adjusted the position of the electrode slightly to direct the electric pulse ventrally into E2.0 embryos so that the genes were transferred mainly into GPCs (Fig. 3a).

Hedgehog-interacting protein (Hip) lacking the last 22 C-terminal amino-acid residues (Hip $\Delta$ C22; Fig. 3a) competitively inhibits binding of Hedgehog ligand to its receptor in the extracellular space ${ }^{34,36}$. Forced expression of Hip $\Delta$ C22 in GPCs led to the downregulation of Hedgehog signalling specifically in these cells $12 \mathrm{~h}$ after electroporation (Supplementary Fig. 6, $n=6)$. In enhanced green fluorescent protein (EGFP)electroporated (control) embryos, GATA4-expressing gonadal primordium started to form ridge structures bilateral to the mesentery at E4.5 (Fig. 3b,e, $n=10$; Fig. 3d,g). By contrast, when Hedgehog signalling was interrupted by $\operatorname{Hip} \Delta \mathrm{C} 22$ at E2.0, no genital ridge was formed at the presumptive gonadal area on the electroporated side. Consistent with this, cells in this region failed to express GATA4 (Fig. 3h,k, $n=5$; Fig. 3j,m). Moreover, when Hip $\triangle$ C22 was overexpressed in GPCs at E3.0, they formed a GATA4 + genital ridge (Supplementary Fig. 7, $n=6$ ). These results indicate that Hedgehog signalling activated in GPCs from E2.0 to E3.0 causes them to differentiate into gonadal cells and form a genital ridge.

To investigate whether Hedgehog signalling endows the gonadal primordium with the ability to attract and retain PGCs, we examined the effect of Hip $\Delta \mathrm{C} 22$ overexpression on the localization of PGCs marked by the expression of SSEA1 or CVH. In chicken embryos, PGCs floating in the blood flow migrate almost equally to the left and right gonad through prospective mesentery (Supplementary Fig. $3, n=4$; Fig. $3 c, f, n=10$; Fig. 3d,g; Supplementary Fig. 8) ${ }^{19,37}$. However, when Hedgehog signalling was inhibited as described above, the PGCs localized ectopically; moreover, they were less abundant in the gonad at electroporated side and more abundant on the untreated side (Fig. 3i,l, $n=5$; Fig. 3j,m; Supplementary Fig. 8), possibly because the gonads did not attract or retain PGCs on the electroporated side and more PGCs were attracted to the gonad on the untreated side. Thus, Hedgehog signalling is indispensable for the settlement of PGCs during the early stage of gonadal development.

SHH is sufficient to trigger gonadogenesis in MCPCs. We next investigated whether overexpressed SHH is capable of inducing gonadal development in MCPCs (Fig. 4a). As shown previously ${ }^{29}$, EGFP-electroporated (control) MCPCs remained as epithelia on a laminin-1-positive basement membrane at E4.5 (Fig. 4b,f, $n=20$ ). By contrast, the overexpression of $\mathrm{SHH}$ along with EGFP in MCPCs caused EGFP-positive cells to localize to the underlying stroma of the mesonephros. This observation indicates that, like GPCs, MCPCs undergo ingression if activated by SHH signalling (Fig. 4j,n; $n=20$ ). In addition, these MCPC-derived cells expressed the gonadal marker GATA4 and formed a ridge similar to the gonadal primordium, whereas EGFP-treated (control) MCPCs did not (Fig. 4c,g, $n=6$; Fig. 4k,o, $n=5$; Fig. $4 \mathrm{e}, \mathrm{i}, \mathrm{m}, \mathrm{q})$.

LHX9 is strongly expressed in the overlying gonadal cortex and only weakly in the underlying mesenchyme of the gonad (Supplementary Fig. 9a-c). Likewise, the expression of LHX9 was observed in the ectopic gonad-like structure derived from

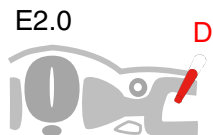

Dil
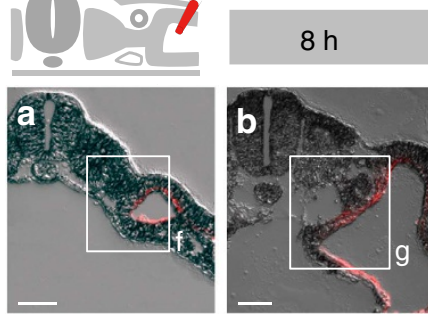

$16 \mathrm{~h}$
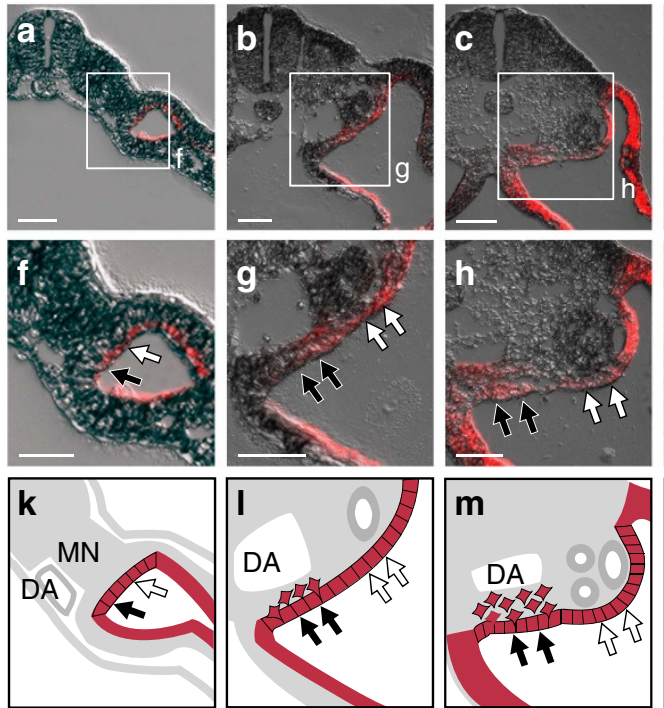

$24 \mathrm{~h}(\mathrm{E} 3)$
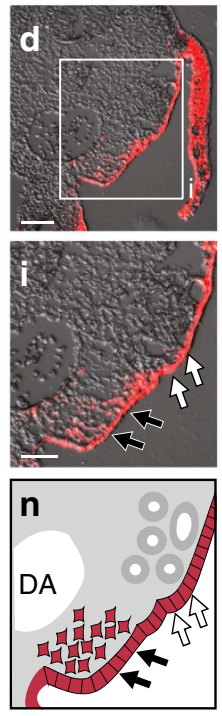
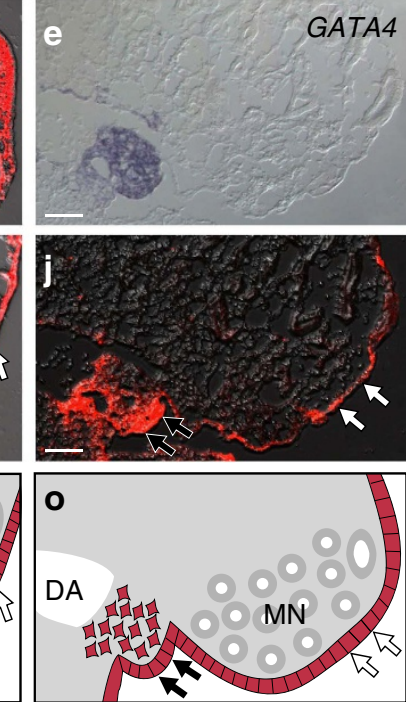

Figure 1 | Localization of GPCs to a particular region of LPM in E2.0 chicken embryos. As illustrated at upper left, Dil was injected into a coelomic space enclosed to label the outer layer of LPM on the right side of chicken embryos at E2.0. (a) Transverse view of an embryo fixed immediately after Dil injection. (b-d) Transverse views of embryos incubated after Dil injection for the periods indicated at the top. (e) GATA4 mRNA expression in the embryo at E4.5. (f-i) Magnified views of the boxed regions in a-d. Black and white arrows indicate GPCs and MCPCs, respectively. (j) Dil labelling in an embryo fixed $60 \mathrm{~h}$ after Dil injection (E4.5). (k-o) Illustrations of $\mathbf{f - j}$. Dil-labelled cells are shown in red. DA, dorsal aorta; MN, mesonephros. Scale bars, $75 \mu \mathrm{m}(\mathbf{a}, \mathbf{c}, \mathbf{d}) ; 50 \mu \mathrm{m}(\mathbf{b}, \mathbf{e}-\mathbf{j})$. 


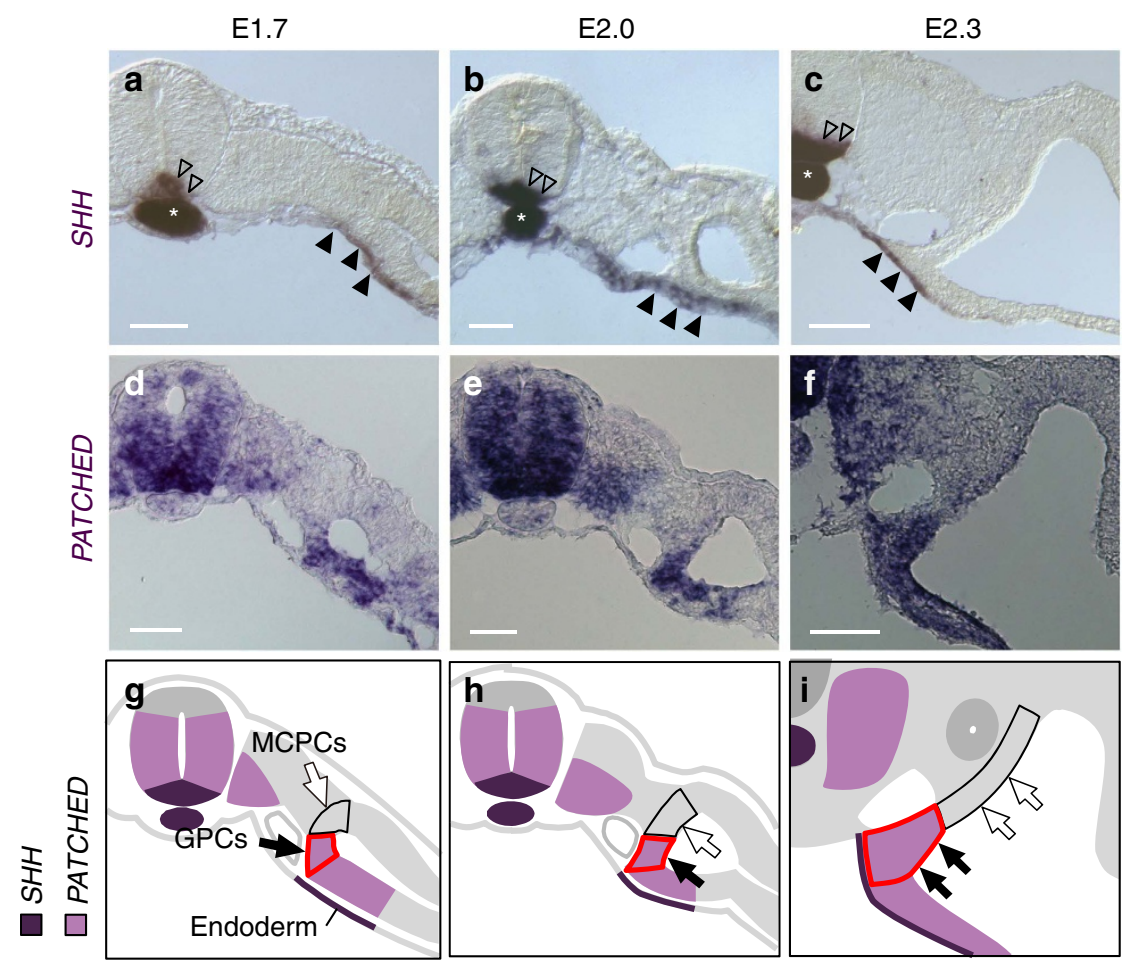

Figure 2 | Activation of Hedgehog signalling in GPCs, but not MCPCs, before gonadogenesis. (a-f) mRNA expression of SHH (a-c) and its target gene PATCHED (d-f) are shown in chicken embryos at E1.7 (a,d), E2.0 (b,e) and E2.3 (c,f). SHH is expressed in the endoderm (black arrowheads) in addition to floor plate (open arrowheads) and notochord (asterisks). (g-i) Localizations of SHH and PATCHED mRNAs are illustrated with dark and light purple, respectively. PATCHED expression was detected in the future gonadal area (outlined in red) composed of coelomic epithelium (black arrows) and coelomic epithelial cell-derived underlying mesenchyme adjacent to the endoderm. PATCHED expression was not detected in MCPCs, which are more distant from the endoderm (white arrows). Scale bars, $50 \mu \mathrm{m}$.

MCPCs stimulated by overexpressed SHH (Supplementary Fig. 9d-j). Furthermore, PGCs localized to the mesonephros in addition to the gonad, and were surrounded by EGFP-positive cells derived from MCPCs, whereas PGCs did not localize to the mesonephros of control embryos (Fig. 4d,h, $n=6$; Fig. 4l,p, $n=5$; Supplementary Fig. 8). These results indicate that SHH signalling can trigger ectopic gonadogenesis in MCPCs by inducing ingression and well-organized differentiation into gonadal cells that can attract and retain PGCs (Fig. $4 \mathrm{~m}, \mathrm{q}$ ). SHH appeared to activate its downstream signalling pathway specifically in early MCPC-derived cells. PATCHED was expressed in the MCPCderived GFP + cells stimulated by SHH at E3.5, but not E4.5. Furthermore, even in E3.5 embryos, Hedgehog signalling was not upregulated in the underlying mesonephric cells (Supplementary Fig. 10, $n=5$ ). Taken together, these results show that differences in Hedgehog signalling activity are responsible for the distinct behaviours of GPCs and MCPCs of E2.0 embryo, and that Hedgehog signalling orchestrates the onset of gonadogenesis in the GPCs.

The gonadal competence of the LPM in response to SHH appeared to depend on the proximodistal axis in E2.0 embryos. The lateral region of the LPM, neighbouring the MCPC, is called the somatopleural mesoderm, and it forms the body wall by undergoing ingression (Supplementary Fig. 11a) ${ }^{13}$. When SHH was overexpressed in the somatopleural mesoderm proximal to the MCPCs, these cells ectopically formed a well-organized genital ridge structure (in this structure, GATA4 was expressed broadly and LHX9 is expressed in the cortex; all of these properties were similar to those of the untreated gonad; Supplementary Fig. 11b-k, $n=5$ ). By contrast, the overexpression of SHH in somatopleural cells distal to MCPC did not form this structure (Supplementary Fig. 11q-u, $n=5$ ).
Therefore, LPM cells appear to have different gonadal competence along the proximodistal axis at E2.0. Notably, when Hedgehog signalling was activated in MCPCs at E3.0 by SHH overexpression, they underwent neither ingression nor differentiation into gonadal cells (Supplementary Fig. 12, $n=10$ ). This observation suggests that MCPCs lose competence to differentiate into gonad at E3.0. Collectively, these findings indicate that the ability of LPM cells to respond to SHH signalling is spatiotemporally regulated.

Regulation of BMP4 expression in the medial LPM. We next investigated which events were induced in GPCs and MCPCs by Hedgehog signalling. BMP4, which acts downstream of Hedgehog signalling, regulates cell differentiation and migration in many processes, such as embryogenesis and cancer progression ${ }^{24,38}$. Furthermore, BMP4 is upregulated by SHH in the developing gut mesenchyme ${ }^{26,39}$. Therefore, we examined the expression of BMP4 in early chicken embryos. At E1.7, BMP4 is expressed throughout the LPM, including both GPCs and MCPCs, and thus establishes the mediolateral axis in the mesoderm (Fig. $5 \mathrm{a}, \mathrm{d})^{25}$. At E2.0, after gonadogenesis has been triggered, BMP4 mRNA expression was downregulated in MCPCs, but maintained in GPCs (Fig. 5b,c,e,f). BMP4 expression at E2.0 and thereafter was similar to that of PATCHED (Fig. 2h,i). These observations raised the possibility that differential expression of BMP4 is due to the differences in Hedgehog signalling activity in GPCs and MCPCs after E2.0.

To address this question, we co-electroporated two plasmids, pCMV-SHH and pCAGGS-EGFP, into the MCPCs at E2.0 and investigated BMP4 mRNA expression at E3.0 (Fig. 6a). BMP4 was expressed by GPC-derived cells, but not MCPCs, on the untreated side (Fig. 6b, $n=6$ ), whereas on the side with SHH 
a
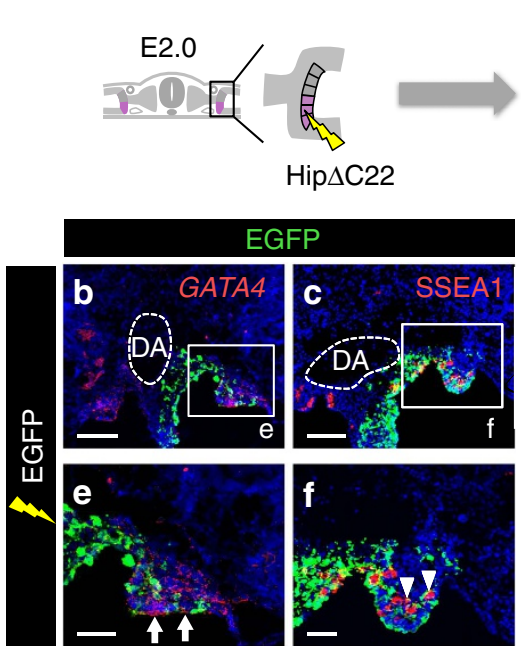

GFP

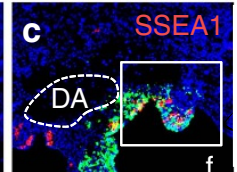

$\square$ Gonadal cell $\left(\right.$ GATA4 $\left.{ }^{+}\right)$ O PGC $\left(\right.$ SSEA $\left.1^{+}\right)$
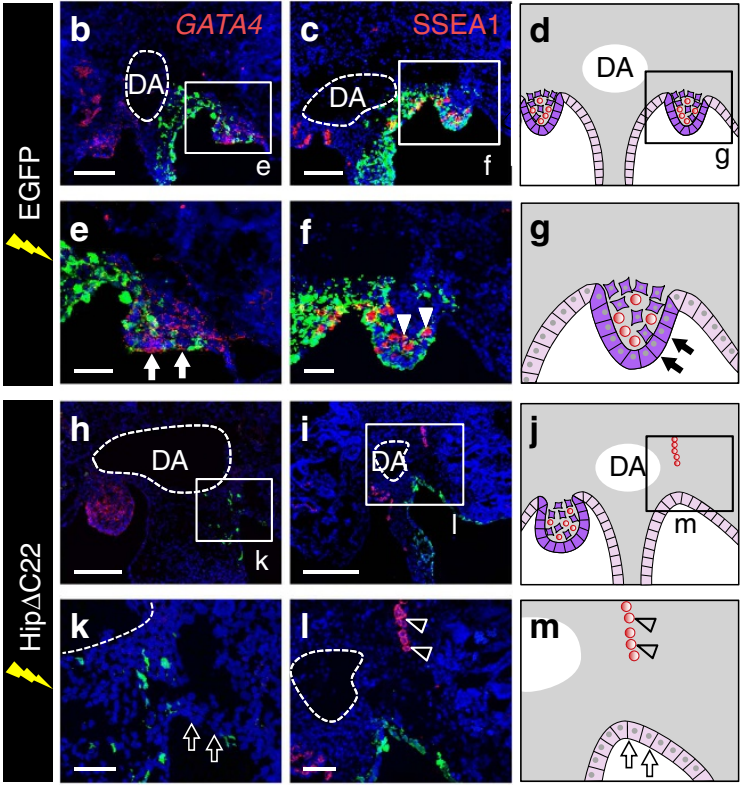

Figure 3 | Hedgehog signalling is essential for gonadal development of GPCs. (a) Expression plasmid for Hip $\Delta$ C22, a secreted Hedgehog antagonist, was electroporated with EGFP expression plasmid into GPCs (pink) at E2.0. (b,c) Boxed region indicated in $\mathbf{a}$ in control EGFP-electroporated embryos (E4.5). GATA4 mRNA (b) and SSEA1-positive primordial germ cells (PGCs) (c) were detected. (d) Illustrations of the development of gonads transfected with EGFP. (e-g) Magnified views of boxed regions in b-d. In control EGFP-electroporated embryos, GATA4-positive cells formed a swell (arrows in $\mathbf{e}$ and $\mathbf{g}$ ) where

SSEA1-positive PGCs localized (arrowheads in $\mathbf{f}$ ). (h,i) Boxed region indicated in $\mathbf{a}$ in embryos (E4.5) transfected with Hip $\Delta \mathrm{C} 22$ showing GATA4 mRNA expression (h) and localization of PGCs (i). (j) Schematic representation of the events in $\mathbf{h}$ and $\mathbf{i}$. (k-m) Magnified views of boxed regions in $\mathbf{h}-\mathbf{j}$. In Hip $\Delta$ C22-overexpressing embryos, GATA4 was not expressed in the presumptive gonadal cells, the genital ridge was not formed (arrows in $\mathbf{k}$ and $\mathbf{m}$ ), and the PGCs scattered (arrowheads in $\mathbf{I}$ and $\mathbf{m})$. DA, dorsal aorta. Scale bars, $100 \mu \mathrm{m}(\mathbf{b}, \mathbf{c}, \mathbf{h}, \mathbf{i}) ; 50 \mu \mathrm{m}(\mathbf{e}, \mathbf{f}, \mathbf{k}, \mathbf{I})$.

overexpression, BMP4 was ectopically expressed in EGFPpositive MCPC-derived cells and their neighbours (Fig. 6c, $n=6)$. When Hedgehog signalling was inhibited in GPCs by electroporation of Hip $\triangle \mathrm{C} 22$ (Fig. 6d), BMP4 expression was downregulated in GPCs on the electroporated side but not on the unelectroporated side (Fig. 6e, $n=6$ ). These results indicate that Hedgehog signalling is responsible for differential expression of BMP4 between GPCs and MCPCs after E2.0.

MCPC and GPC behaviours are determined by BMP signalling. We next investigated whether BMP4 initiates gonadogenesis in MCPCs. To this end, pCAGGS-BMP4 and pCAGGS-EGFP were co-electroporated into MCPCs at E2.0 (Fig. 7a). As shown previously, the EGFP-electroporated (control) MCPCs remained as epithelia on the basement membrane (Fig. 7b,e, $n=20$; Fig. $7 \mathrm{~h})^{29}$ and neither expressed GATA4 (Fig. $7 \mathrm{c}, \mathrm{f}, n=5$ ) nor attracted
PGCs at E4.5 (Fig. 7d,g, $n=6$ ). By contrast, the overexpression of BMP4 initiated ingression of MCPCs to the underlying stroma (Fig. 7i,l, $n=5$; Fig. 7o). These MCPC-derived cells and their neighbours ectopically expressed GATA4 and LHX9, although they did not form a genital ridge-like structure (Fig. $7 \mathrm{j}, \mathrm{m}, n=5$; Fig. 7o; Supplementary Fig. 9k-m, $n=5$ ). Furthermore, the BMP4-overexpressing MCPC-derived cells attracted PGCs to their vicinity (Fig. 7k,n, $n=5$; Fig. 7o; Supplementary Fig. 8). These results indicate that BMP signalling induces ingression of MCPC and differentiation into gonadal cells that can retain PGCs. Moreover, when BMP4 was overexpressed in the somatopleure proximal to MCPC, which formed an ectopic gonad on SHH overexpression, gonadogenesis was not complete: although these BMP4-overexpressing cells ectopically expressed GATA4, they did not express LHX9 (Supplementary Fig. 11l-p, $n=6)$.

We next investigated whether GPCs require BMP signalling to initiate gonadal differentiation. To this end, we electroporated the secretory BMP antagonist Noggin ${ }^{25,40}$ into GPCs and investigated whether the gonad was formed at E4.5 (Fig. 8a). We observed neither the expression of GATA4 nor the formation of a genital ridge at the Noggin-overexpressing side (Fig. $8 \mathrm{~h}, \mathrm{k}, n=5$; Fig. $8 \mathrm{~m}$ ). By contrast, EGFP-overexpressing (control) GPCs or untreated GPCs formed a GATA4-positive genital ridge (Fig. 8b,e, $n=10$; Fig. 8d,g; Fig. 8h, $n=5$; Fig. 8j).

SSEA1-positive PGCs localized to the genital ridge derived from EGFP-overexpressing (control) GPCs (Fig. 8c,f, $n=10$; Fig. 8g). By contrast, in Noggin-overexpressing embryos, PGCs did not localize to the presumptive gonadal region at the electroporated side. Instead, more PGCs were retained at the genital ridge on the untreated control side (Fig. 8i,l, $n=10$; Fig. 8m; Supplementary Fig. 8). Although Noggin inhibits BMP2 and BMP7 as well as BMP4 (ref. 41), BMP2 and BMP7 mRNAs were not detected in the GPCs or surrounding cells at E2.0 (Supplementary Fig. 13). Taken together, these findings indicate that altered BMP4 expression at E2.0 established a dorsal (MCPCs) and ventral (GPCs) patterning in the medial LPM and orchestrates GPC behaviours to initiate gonadogenesis downstream of Hedgehog signalling.

\section{Discussion}

In most multicellular organisms, the gonad is essential for the production of offspring. However, the molecular mechanism underlying the onset of gonadogenesis in vertebrates has remained largely unexplored, mainly because the location of GPCs within the LPM and the precise timing of the onset of gonadogenesis remained unknown. In this study, we demonstrated that GPCs are positioned at the ventromedial LPM, and that these cells initiate gonadogenesis by undergoing ingression in chicken 2-day (E2.0) embryos. Meanwhile, the dorsomedial LPM cells covering the mesonephros (MCPCs) maintain their epithelial integrity. These distinct behaviours of GPC and MCPC appear to be controlled by Hedgehog signalling. Subsequent to these events, Hedgehog signalling triggers gonadal differentiation by activating BMP4 expression in GPCs (Fig. 8n).

The earliest morphogenetic event of gonadogenesis is considered to be the emergence of the epithelial thickening called the genital ridge, which is identifiable starting at E3.0 in chicken and E10.0 in mouse embryos ${ }^{28}$. Here we showed that GPCs start undergoing ingression as early as E2.0 in chicken embryos (Fig. 1). As far as we know, this is the earliest tissue/cellular sign of gonadogenesis reported to date.

This earliest event of gonadal development is most likely evoked by $\mathrm{SHH}$ emanated from endoderm. Moreover, it is noteworthy that $\mathrm{SHH}$ overexpression also caused multiple 
a
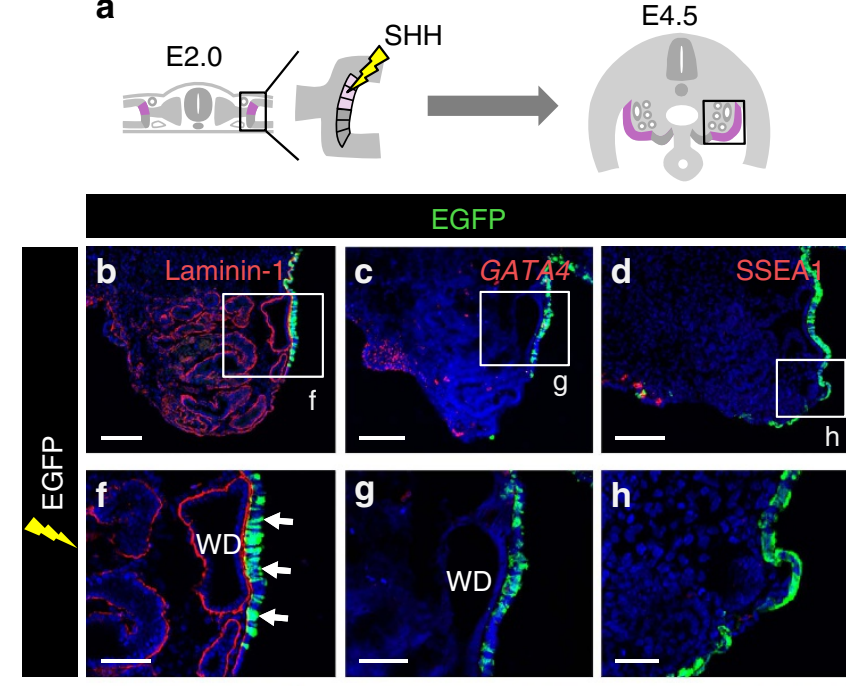

$\square$ Gonadal cell

\section{OPGC}
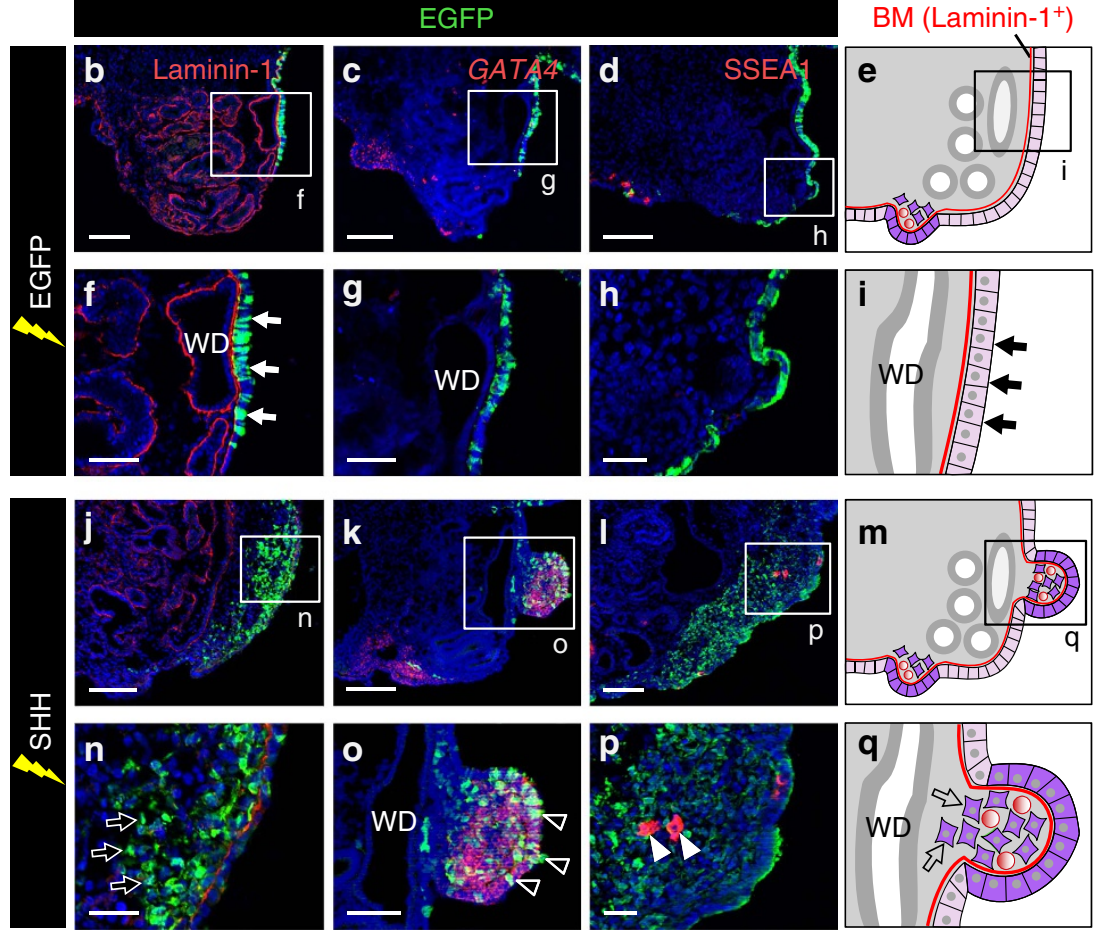

Figure 4 | Ectopic gonadogenesis in MCPCs is triggered by SHH. (a) SHH expression plasmid was electroporated into MCPCs (pale pink) at E2.0. (b-d) Transverse views (corresponding to the boxed region in a) of the mesonephros in the E4.5 EGFP-electroporated control embryo. Images depict staining for laminin-1 protein (b), GATA4 mRNA (c) or SSEA1 protein (d). (e) Illustrations of MCPC-derived cells after overexpression of control EGFP. (f-i) Magnified views of boxed region in b-e. The Wolffian duct (WD) is indicated. In control EGFP-electroporated embryos, MCPCs remained as epithelia (arrows in $\mathbf{f}$ and $\mathbf{i}$ ) overlying a basement membrane (BM, laminin-1 positive) and did not express GATA4 mRNA (g) or attract SSEA1-positive PGCs (h). (j-I) Boxed area in a in an SHH-transfected embryo, showing the distribution of laminin-1 (j), GATA4 mRNA (k) or SSEA1-positive PGCs (I). (m) Illustrations of SHH-overexpressing MCPC-derived cells. (n-q) Magnified views of $\mathbf{j}-\mathbf{m}$. SHH overexpression caused MCPCs to undergo ingression (arrows in $\mathbf{n}$ and $\mathbf{q}$ ), to express GATA4 mRNA (o and $\mathbf{q}$ ), often to begin forming a swell (arrowheads in $\mathbf{o}$ ) and to retain ectopically localized SSEA1-positive PGCs (arrowheads in p). Scale bars, $100 \mu \mathrm{m}$ (b-d,j-1); $25 \mu \mathrm{m}(\mathbf{f}, \mathbf{g}, \mathbf{0}) ; 50 \mu \mathrm{m}(\mathbf{h}, \mathbf{n}, \mathbf{p})$.

E1.7

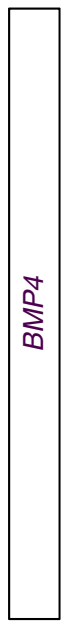

E2.0
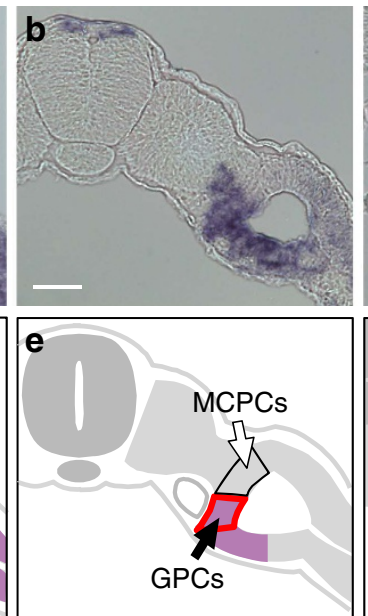

E2.3

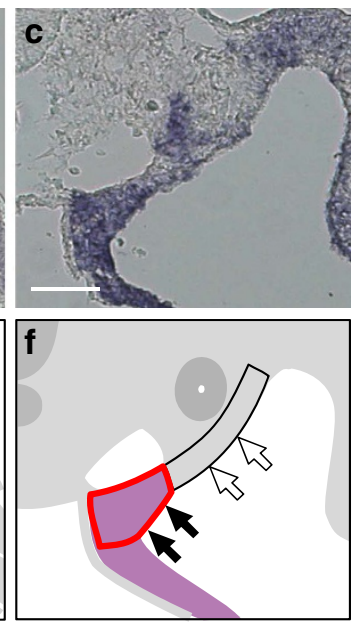

Figure 5 | Transition of BMP4 expression pattern in GPCs and MCPCs of E2 embryos. Transverse views of embryos at E1.7, E2.0 and E2.3 showing mRNA expression of BMP4 (a-c); illustrations are shown in (d-f). BMP4 was expressed in the entire LPM of the E1.7 embryo (d). Expression disappeared in MCPCs (white arrows) but was maintained in the future gonadal area (outlined in red), including the gonadal coelomic epithelium (black arrows) and coelomic epithelial cell-derived underlying mesenchyme at E2.0 (e) and later (f). Scale bars, $50 \mu \mathrm{m}$. 
a
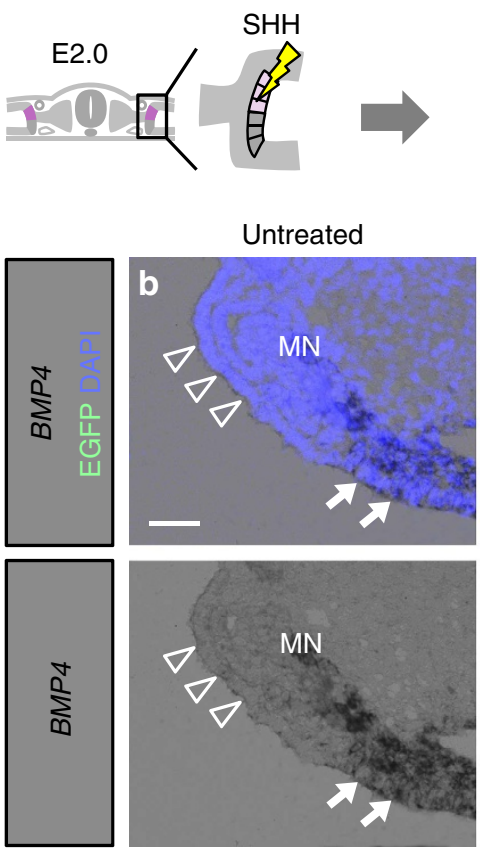

d
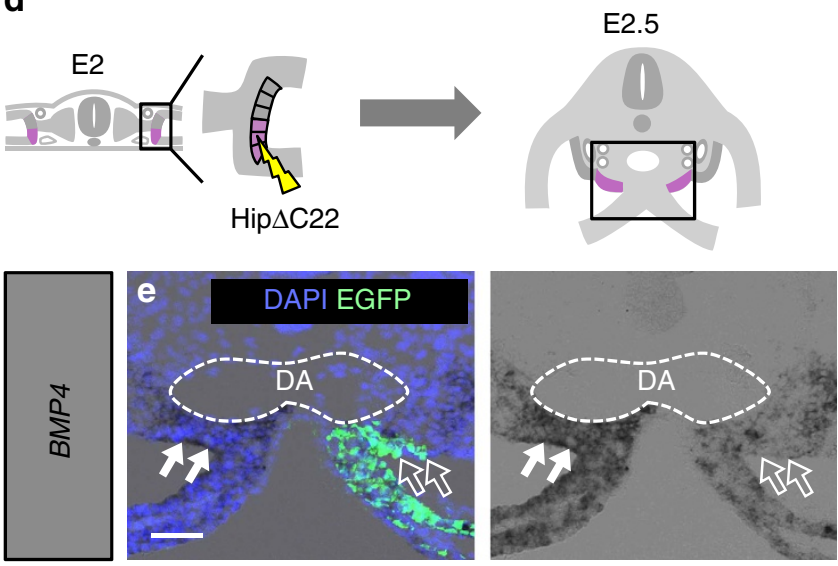

Figure 6 | Differential BMP4 expression in GPCs versus MCPCs induced by Hedgehog signalling. (a) $\mathrm{SHH}$ expression plasmid was electroporated into MCPCs at E2.0. (b,c) Transverse views of the mesonephros and presumptive gonad, corresponding to the boxed regions in $\mathbf{a}$, at the untreated (control) side (b) or SHH-overexpressing side (c), stained for BMP4 mRNA. BMP4 expression was detected in the presumptive gonad (arrows in $\mathbf{b}$ ) but not in the MCPCs (open arrowheads in $\mathbf{b}$ ) on the untreated (control) side, but was detected in both MCPCs (white arrowheads in c) and GPCs (arrows in c) on the $\mathrm{SHH}$-overexpressing side. (d) Hip $\Delta C 22$ expression plasmid was electroporated into the GPCs in E2.0 embryos. (e) Transverse views of the presumptive gonadal region, corresponding to the boxed regions in d. BMP4 expression was downregulated in the Hip $\Delta$ C22-electroporated side (open arrows) relative to the untreated (control) side (white arrows). MN: mesonephros; DA: dorsal aorta. Scale bars, $50 \mu \mathrm{m}$.

features normally observed during gonadal development, including formation of the genital ridge-like structure and collection of PGCs. Collectively, these data show that SHH is the most upstream molecule involved in triggering and orchestration of gonadogenesis in chicken.

In this study, we demonstrated that GATA4 and LHX9, which are gonadogenesis-related transcription factors in mouse $\mathrm{e}^{16,17}$, are downstream targets of Hedgehog signalling in chicken. Moreover, we found that BMP4 regulates gonadal initiation downstream of Hedgehog signalling. In chicken, forced expression of BMP4 enabled MCPCs to show several aspects of gonadal initiation, but could not induce the formation of a genital ridge-like structure in and around MCPCs. These results imply that Hedgehog signalling controls downstream molecules in addition to BMP4 to form the ridge structure.

In addition, we demonstrated that expression patterns of BMP4 dynamically change before and after gonadal initiation. Before E2.0, BMP4 is broadly expressed in LPM cells including MCPCs and GPCs, and form the LPM structure ${ }^{25}$. Subsequently, BMP4 expression is restricted only to GPCs after E2.0. An appropriate transition of $B M P 4$ expression might be important for correct formation of the LPM and subsequent gonadal initiation. Future studies should seek to elucidate the mechanisms underlying this transition in BMP4 expression, in which Hedgehog signalling plays an essential role.

We also found that ectopic gonadal induction by forced expression of $\mathrm{SHH}$ or BMP4 depended on the position within the LPM, as well as on developmental stage. In E2.0, MCPCs could respond to both $\mathrm{SHH}$ and $\mathrm{BMP} 4$, nearby proximal somatopleural cells could respond to $\mathrm{SHH}$ but not to BMP4, and distal somatopleural cells far from MCPCs could respond to neither. At E3.0, MCPCs no longer responded to SHH. Thus, gonadal competence seems to be regulated within LPM cells in a spatiotemporal manner. This regulation might contribute to placing gonads in the correct position or to the robustness of gonadal formation.

Although SHH and BMP4 play central roles in the initiation of gonadal differentiation in chicken embryos, these molecules have not been shown to be necessary in mice so far ${ }^{42,43}$. However, Shh and Bmp4 are expressed in mice embryo in a manner similar to the chicken ${ }^{32,44}$. Furthermore, primary cilia responsible for the distribution of secreted Hedgehog affect the gonadal length, and BMP signalling is required for correct localization of PGCs at the early genital ridge in mice ${ }^{44,45}$. Hedgehog and Bmp4 signalling might be involved in the initiation of gonadal differentiation in mouse embryos. It would be interesting to determine whether, and to what extent, gonadal initiation processes vary among amniotes.

\section{Methods}

Chicken embryos. Fertilized chicken eggs were commercially obtained from the Shiroyama Farm (Sagamihara, Japan). All animal experiments were conducted with the ethical approval of Kyoto University (No.H2620).

DNA constructions. The pCMV-SHH was a gift from Dr T. Ogura (Tohoku University). The cDNAs for mouse Hip $\triangle C 22$ and chicken BMP4 and Noggin were PCR-amplified using the following primers: mouse Hip $\triangle C 22,5^{\prime}$-TTTACGCGTAT GCTGAAGATGCTCTCGTT- $3^{\prime}$ and $5^{\prime}$-TTTGCTAGCCTACCTGGTCACTCTGC GGAC-3'; chicken BMP4, 5'-AATTACGCGTATGATTCCTGGTAACCGAAT- $3^{\prime}$ and $5^{\prime}$-ATCTGATATCAGCGGCACCCGCACCCCT-3'; chicken Noggin, $5^{\prime}$-AAT TCTCGAgATGGATCATTCCCAGTGCCT- $3^{\prime}$ and $5^{\prime}$-ATCTGATATCTAGCAGG AGCACTTGCACT- $3^{\prime}$. The amplified fragments were digested with MluI-NheI, MluI-EcoRV or XhoI-EcoRV and subcloned into pCAGGS.

Dil labelling. DiI (Invitrogen) was dissolved in ethanol $(0.1 \%)$, heated at $45^{\circ} \mathrm{C}$ for $3 \mathrm{~min}$ and diluted 1:10 with $0.3 \mathrm{M}$ sucrose. This solution was injected into the coelom of the right side of E2.0 embryos using a glass capillary. Thereafter, the embryos were incubated for various time periods, killed, fixed overnight at $4{ }^{\circ} \mathrm{C}$ in PBS containing $4 \%$ paraformaldehyde (PFA) and sectioned by cryostat at $10-\mu \mathrm{m}$ thick on Platinum Pro-coated glass slides (Matsunami). Images were obtained on an AxioPlanII microscope with the Apotome system (Carl Zeiss).

Immunostaining. Laminin-1 was detected as follows. After pre-blocking with blocking solution ( $1 \%$ blocking reagent (Roche)/0.1 M Tris- $\mathrm{HCl}(\mathrm{pH} 7.5), 0.15 \mathrm{M}$ $\mathrm{NaCl}, 0.1 \%$ Tween 20 (TNT)) for $1 \mathrm{~h}$ at room temperature (RT), the sections were incubated at $4{ }^{\circ} \mathrm{C}$ overnight using an anti-laminin-1 antibody (mouse 3H11, DSHB, 
a
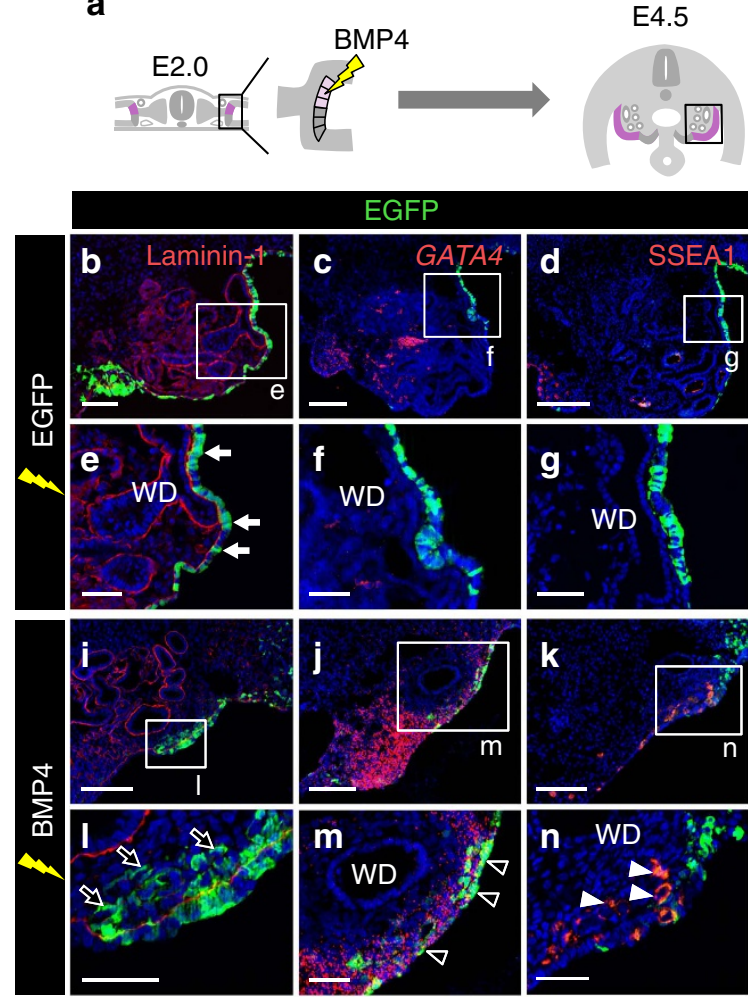

$\square$ Gonadal cell

O PGC

Basement membrane
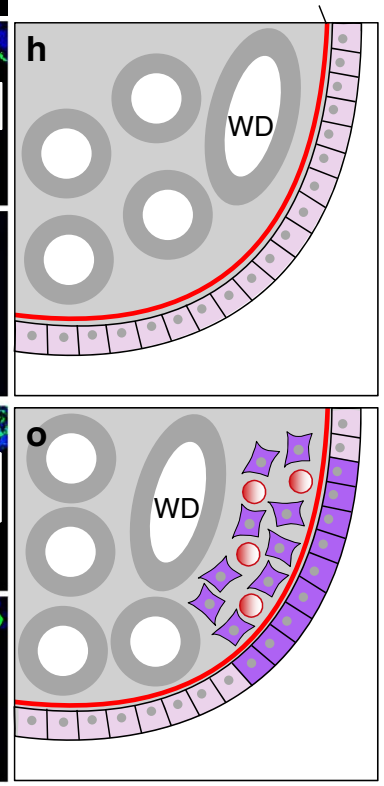

Figure 7 | Gonadogenesis in MCPCs induced by BMP4. (a) BMP4 cDNA was electroporated into MCPCs. (b-d) Transverse views of the E4.5 mesonephros after electroporation with control EGFP. Distributions of laminin-1, GATA4 mRNA and SSEA1-positive PGCs are shown. (e-g) Magnified views of the boxed regions in b-d. MCPCs that remained as epithelia after electroporation with control EGFP (arrows in $\mathbf{b}$ ). (h) Illustrations of control EGFP-overexpressing mesonephros. (i-k) Boxed region indicated in a in a BMP4-electroporated embryo. Laminin-1, Gata4 mRNA and SSEA1-positive PGCs were detected. (I-n) Magnified views of the boxed regions in i-k. BMP4-overexpressing MCPC-derived cells were located in underlying kidney stroma (arrows in I), expressed GATA4 mRNA (arrowheads in $\mathbf{m}$ ) and induced ectopic localization of SSEA1-positive PGCs to their vicinity (arrowheads in n). (o) Illustrations of BMP4-overexpressing mesonephros. WD: Wolffian duct. Scale bars, $100 \mu \mathrm{m}$ (b-d,i-k); $40 \mu \mathrm{m}(\mathbf{e}-\mathbf{g}, \mathbf{I}-\mathbf{n})$.

1:400). After three washes in TNT, the specimens reacted with anti-mouse IgGAlexa Fluor 568-conjugated goat antibody (Invitrogen) diluted 1:500 with blocking solution for $1 \mathrm{~h}$ at RT. The sections were washed three times in TNT and sealed with FluorSave reagent (Calbiochem). To detect SSEA1, atypical PKC or CVH, cryostat sections were treated with $3 \% \mathrm{H}_{2} \mathrm{O}_{2}$ in TNT for $30 \mathrm{~min}$, washed three times in TNT and preblocked. The specimens were reacted with a 1:300 dilution of anti-SSEA1 (mouse MC-480, DSHB), anti-PKCל (rabbit sc-216; Santa Cruz Biotechnology) or anti-CVH (rat, see also Supplementary Method) antibodies, and subsequently reacted with a 1:300 dilution of horseradish peroxidase (HRP)conjugated anti-mouse IgM (rat 1B4B1, Southern Biotech), HRP-conjugated anti-rabbit IgG (donkey, Amersham Bioscience) or HRP-conjugated anti-rat IgG (donkey, Abcam). After three washes in TNT, the specimens were reacted with Tyramide Signal Amplification (TSA) plus Cy3 (PerkinElmer) for 5 min at RT. The sections were then washed three times in TNT and sealed. Fluorescence images were obtained on an Axioplan 2 microscope with the Apotome system.

Section in situ hybridization. After two washes in TNT, cryostat sections were treated with hybridization buffer (Ultra Hyb; Ambion) and incubated for $5 \mathrm{~min}$ at $65^{\circ} \mathrm{C}$. The hybridization was carried out overnight at $65^{\circ} \mathrm{C}$ in hybridization buffer containing a DIG-labelled RNA probe $\left(1 \mathrm{ng} \mathrm{ml}^{-1}\right)$. The sections were rinsed and washed in wash solution 1 ( $50 \%$ formamide, $5 \times$ SSC, pH 4.5 , and $1 \%$ SDS) at $65^{\circ} \mathrm{C}$ for $30 \mathrm{~min}$, washed twice for $30 \mathrm{~min}$ each in wash solution $2(50 \%$ formamide and $2 \times \mathrm{SSC}, \mathrm{pH} 4.5)$ at $65^{\circ} \mathrm{C}$, and washed in a 1:1 mixture of wash solution 2 and TNT for $5 \mathrm{~min}$ at $65^{\circ} \mathrm{C}$, followed by three washes in TNT. The sections were then preblocked, followed by an overnight incubation at $4{ }^{\circ} \mathrm{C}$ in a blocking solution containing an anti-DIG-alkaline phosphatase-conjugated antibody (Roche). After three washes in TNT, the sections were processed in $100 \mathrm{mM}$ Tris- $\mathrm{HCl}$ ( $\mathrm{pH} 9.5$ ), $100 \mathrm{mM} \mathrm{NaCl}, 50 \mathrm{mM} \mathrm{MgCl} 2,0.1 \%$ Tween 20 (NTMT)/2 mM levamisole. Alkaline phosphatase activity was visualized by incubating specimens in NTMT containing $0.07 \mathrm{mg} \mathrm{ml}^{-1}$ nitroblue tetrazolium chloride (Roche), $0.035 \mathrm{mg} \mathrm{ml}^{-1}$ 5-bromo-4chloro-3-indolyl phosphate (Roche) and $2 \mathrm{mM}$ levamisole. After the colour reaction was stopped by washing twice in TNT, the sections were mounted in FluorSave reagent with 4,6-diamidino-2-phenylindole. Images were obtained on an Axioskop 2 plus microscope (Carl Zeiss).
In ovo electroporation. Expression plasmids were suspended in EB buffer (Qiagen) containing 2\% Fast Green FCF (Nacalai Tesque) and 8\% sucrose. The DNA solution was injected into the coelom of the right side of E2.0 or E3.0 embryos with a glass capillary. For transfection of the DNA into MCPC or GPC of E2.0 embryos, a minus electrode (tungsten) and plus electrode (platinum) were placed on the right and left side of the embryo, respectively. By contrast, to transfer genes into the somatopleure of E2.0 embryos or the MCPC of E3.0 embryos, the minus and plus electrodes were set at the lower and upper ends of the embryo, respectively. Thereafter, an electric pulse (E2.0 embryo: $75 \mathrm{~V}(0.05 \mathrm{~ms}$ ON/ $1 \mathrm{~ms}$ $\mathrm{OFF})$ and five timed pulses of $20 \mathrm{~V}(25 \mathrm{~ms}$ ON/475 ms OFF); E3.0 embryo $75 \mathrm{~V}$ $(0.05 \mathrm{~ms} \mathrm{ON} / 1 \mathrm{~ms} \mathrm{OFF})$ and five timed pulses of $25 \mathrm{~V}(25 \mathrm{~ms} \mathrm{ON} / 475 \mathrm{~ms}$ OFF $))$ was applied using a CUY21 EX (BEX).

Probes. Chicken cDNA fragments for $S H H$ and PATCHED were provided by Dr C. Tabin (Harvard University). Chicken $I H H$ cDNA fragments were given by Dr T. Suzuki (Nagoya University). The cDNAs for chicken BMP2, BMP4, BMP7, GATA4 and LHX9 were obtained by PCR using the following primers: Chicken BMP2, $5^{\prime}$-GCCTCTCGAGATGGTTGCCGCCACCCGCTC- $3^{\prime}$ and $5^{\prime}$-ATCTGA TATCAGCGGCACCCGCAGCCCT-3'; Chicken BMP4, 5' -AATTACGCGTAT GATTCCTGGTAACCGAAT- ${ }^{\prime}$ and $5^{\prime}$-ATCTGATATCAGCGGCACCCGCACC CCT-3'; Chicken BMP7, 5'-GCCTCTCGAGATGCATTCCCAGAGCGTTCA-3' and $5^{\prime}$-ATCTGATATCTAATGACAGCCGCATGCTC-3';

Chicken GATA4, 5' -GCCTCTCGAGATGTACCAGAGCTTAGCCAT- $3^{\prime}$ and $5^{\prime}$-ATCTGATATCTTATGCCGTTATGATGTCCC-3'; Chicken LHX9, 5'-GCCTC TCGAGATGCTTTTCCACGGGATCTC- $3^{\prime}$ and $5^{\prime}$-ATCTGATATCTTAGAAA AGGTTCGTTAAGG-3'. The amplified fragments were digested by MluI-EcoRV or XhoI-EcoRV and subcloned into pBluescript or pCMS. Digoxigenin- or DNP-labelled RNA probes were prepared according to the manufacturer's instructions (Roche).

Preparation of an anti-CVH antibody. A full-length $C v h$ cDNA fragment was subcloned in-frame into pGEX-5X3 (Pharmacia). The GST-CVH fusion protein was purified using a GST fusion system (Pharmacia) according to the manufacturer's instructions. The purified protein $(300 \mathrm{mg})$ was injected into a rat. 

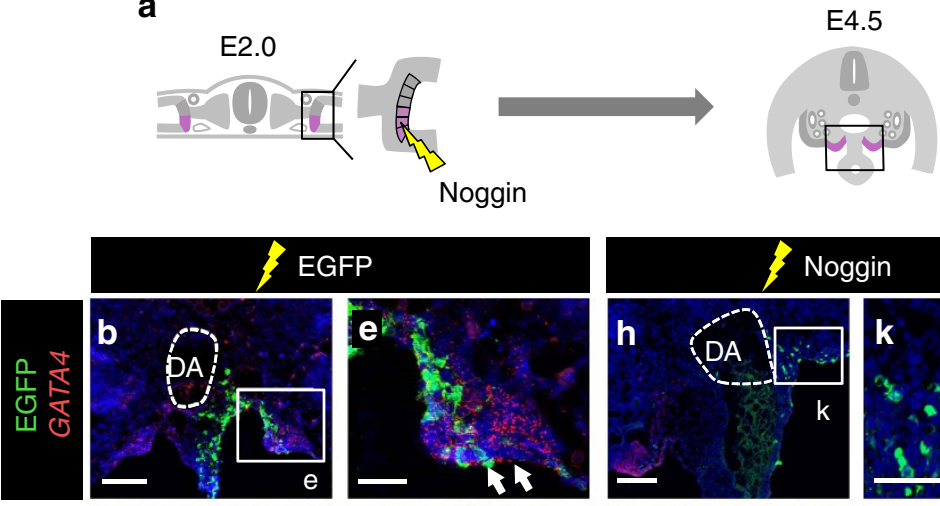

EGFP

高
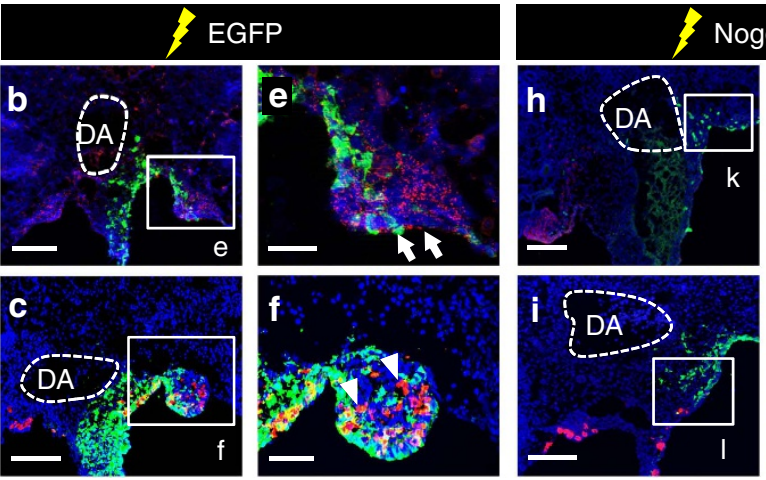

Noggin
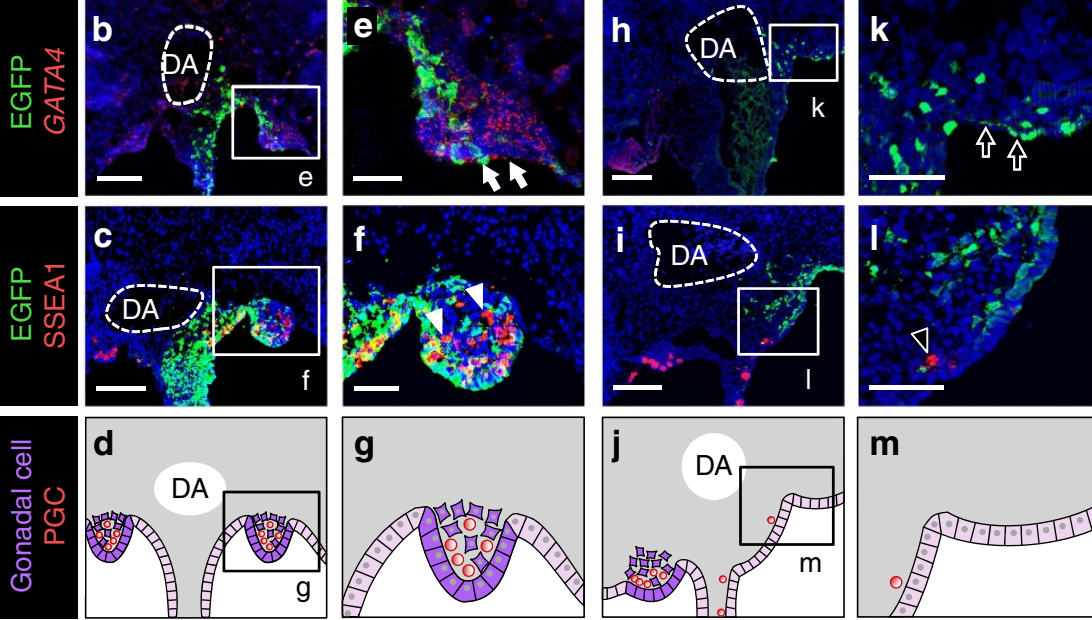

n
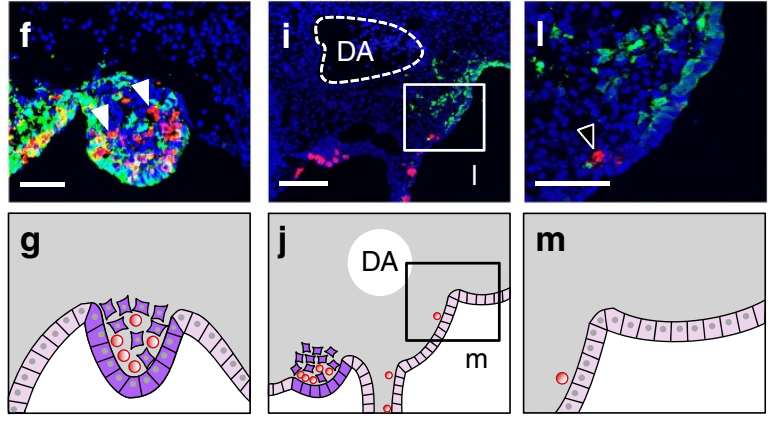

E2.0

E4.5

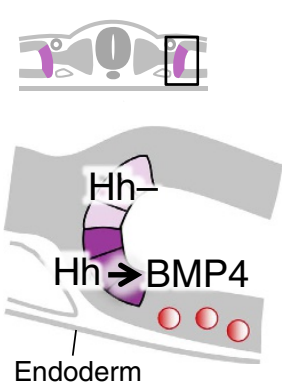

$\left(\mathrm{SHH}^{+}\right)$

GPC

MCPC

OPGC

Figure 8 | BMP signalling is necessary for GPCs to form gonad. (a) GPCs were transfected with Noggin expression plasmid. (b-d) Transverse views and a illustration, corresponding to the boxed region in a in a control EGFP-electroporated embryo. (e-g) Magnified views of the boxed regions in $\mathbf{b}-\mathbf{d}$. The gonad was observed as a swell that expressed GATA4 (arrows in $\mathbf{e}$ ) and retained PGCs (arrowheads in $\mathbf{f}$ ), as illustrated in $\mathbf{g}$. (h-j) Transverse views of gonad in Noggin-overexpressing embryo. (k-m) Magnified views of the regions outlined in $\mathbf{h}-\mathbf{j}$. No GATA4-expressing swell formed at the presumptive gonadal region (arrows in $\mathbf{k}$ ), and PGCs were scattered rather than gathered (arrowhead in I), as illustrated in $\mathbf{m}$. (n) A scheme summarizing our findings. In E2.0 embryos, GPCs are localized at a site facing dorsal aorta (DA). Hedgehog signalling (Hh) is activated in GPCs but not MCPCs, and this Hedgehog signalling triggers gonadogenesis by causing GPCs to undergo ingression, inducing GATA4 expression and creating PGC niche activity, through BMP4 expression. $\mathrm{SHH}$, a Hedgehog ligand, is expressed in endoderm, adjacent to the GPCs and more distant from the MCPCs. Scale bars, $100 \mu \mathrm{m}(\mathbf{b}, \mathbf{c}, \mathbf{h}, \mathbf{i}) ; 50 \mu \mathrm{m}(\mathbf{e}, \mathbf{f}, \mathbf{k}, \mathbf{l})$.

The resulting antiserum was purified by affinity chromatography using GST-CVH-conjugated agarose beads, and was used as an anti-CVH antibody.

Double visualization of mRNA and EGFP protein. The double visualization of mRNA with fluorescent protein signals was performed as follows. Sections were treated with $3 \% \mathrm{H}_{2} \mathrm{O}_{2}$ in methanol for $30 \mathrm{~min}$, and then washed three times for 5 min each in TNT (0.1 mM Tris- $\mathrm{HCl} \mathrm{pH} \mathrm{7.5,} 0.15 \mathrm{mM} \mathrm{NaCl}$ and $0.1 \%$ Tween 20). They were then incubated with hybridization buffer (Ultra hyb; Ambion) for 5 min at $65^{\circ} \mathrm{C}$. Hybridization was carried out with a DNP-labelled RNA probe $\left(1 \mathrm{ng} \mathrm{ml}^{-1}\right)$. The sections were washed with wash solution 1 (50\% formamide, $5 \times$ SSC, $\mathrm{pH} 4.5$, and $1 \%$ SDS), wash solution $2(50 \%$ formamide and $\times$ SSC, $\mathrm{pH} 4.5)$ at $65^{\circ} \mathrm{C}$, and a 1:1 mixture of wash solution 2 and TNT. After washing three times in TNT for 5 min each at RT, the specimens were preblocked with blocking solution ( $1 \%$ blocking reagent (Roche)/TNT) for $1 \mathrm{~h}$ at RT, followed by overnight incubation at $4{ }^{\circ} \mathrm{C}$ in the blocking solution containing 1:1,000 dilutions of an anti-DNP-HRP-conjugated antibody (PerkinElmer) and anti-GFP antibody (rabbit, Invitrogen). After three washes in TNT, the specimens were reacted with TSA plus Cy3 system for $10 \mathrm{~min}$ at RT. The reaction was terminated by washing three times in TNT. To visualize EGFP, the sections were incubated with an anti-rabbit IgG-Alexa 488-conjugated goat antibody (Invitrogen) diluted 1:500 in blocking solution, for $1 \mathrm{~h}$ at RT.

To detect mRNA with NBT/BCIP, sections were incubated with hybridization buffer for $5 \mathrm{~min}$ at $65^{\circ} \mathrm{C}$ after two washes in TNT. The solution was replaced with prewarmed hybridization buffer containing Dig-labelled RNA probes and incubated overnight at $65^{\circ} \mathrm{C}$. The sections were washed with wash solution 1, wash solution 2, and a 1:1 mixture of wash solution 2 and TNT. After three washes in TNT, the samples were preblocked and incubated overnight at $4{ }^{\circ} \mathrm{C}$ in the blocking solution containing an anti-DIG-alkaline phosphatase-conjugated antibody and anti-GFP antibody. The samples were washed three times in TNT, followed by washing in NTMT (100 mM Tris-HCl, pH 9.5, $100 \mathrm{mM} \mathrm{NaCl}, 50 \mathrm{mM} \mathrm{MgCl}_{2}$ and $0.1 \%$ Tween 20$) / 2 \mathrm{mM}$ Levamisole. The alkaline phosphatase activity was visualized by incubating the samples in NTMT containing nitroblue tetrazolium chloride, 5-bromo-4-chloro-3-indolyl phosphate and levamisole. The colour 
reaction was stopped by TNT washing, and then the sections were mounted. Images were obtained using a TCS SP6 microscope (Leica).

Depletion of axial structures and explant culture. The surgical manipulations were performed on E2 embryos. A slit was made between the neural tube and right somite along the anteroposterior axis, with a sharpened tungsten needle. The embryo was then separated into a right axial structure-depleted side and a left control side. Both parts were fixed with PFA soon after the manipulation or incubated for $4 \mathrm{~h}$ at $38^{\circ} \mathrm{C}$ on a $0.8-\mu \mathrm{m}$ filter (Millipore) placed in a $6-\mathrm{cm}$ Center-Well Culture Dish (Falcon) containing 10\% fetal bovine serum/DMEM (Nissui).

\section{Visualization of CVH and EGFP proteins in whole E4.5 embryos}

Double-fluorescent visualization of $\mathrm{CVH}$ and EGFP was performed as follows: E4.5 embryos were fixed with $4 \%$ PFA/PBS overnight at $4{ }^{\circ} \mathrm{C}$, and then washed three times for $30 \mathrm{~min}$ each in $100 \mathrm{mM}$ Tris- $\mathrm{HCl}(\mathrm{pH} 7.5), 150 \mathrm{mM} \mathrm{NaCl}, 0.1 \%$ Tween $20,0.1 \%$ TritonX (TNTT). The fixed embryos were treated with $2 \%$ blocking reagent (Roche)/TNTT for $60 \mathrm{~min}$, incubated with $1 / 1,000$ anti-CVH antibody (rat) and 1/1,000 anti-EGFP antibody (Clontech) in $2 \%$ blocking reagent (Roche)/TNTT overnight at $4^{\circ} \mathrm{C}$, and washed four times for $30 \mathrm{~min}$ each with TNTT. The embryos were then incubated with 1/500 Alexa Fluor 568-conjugated anti-rat antibody and 1/500 Alexa Fluor 488-conjugated anti-rabbit antibody (Invitrogen) diluted in $2 \%$ blocking reagent (Roche)/TNTT overnight at $4{ }^{\circ} \mathrm{C}$, and washed four times for $30 \mathrm{~min}$ each in TNTT. To make samples transparent, they were finally treated with $75 \%$ glycerol/TNTT for $60 \mathrm{~min}$. Images were obtained on an MVX10 microscope (Olympus).

Data availability. Data supporting the findings of this study are available within the article and its Supplementary Information files and from the corresponding author on reasonable request.

\section{References}

1. Spradling, A., Fuller, M. T., Braun, R. E. \& Yoshida, S. Germline stem cells. Cold Spring Harb. Perspect. Biol. 3, a002642 (2011).

2. Matzuk, M. M., Burns, K. H., Viveiros, M. M. \& Eppig, J. J. Intercellular communication in the mammalian ovary: oocytes carry the conversation. Science 296, 2178-2180 (2002).

3. Larney, C., Bailey, T. L. \& Koopman, P. Switching on sex: transcriptional regulation of the testis-determining gene Sry. Development 141, 2195-2205 (2014).

4. Barske, L. A. \& Capel, B. Blurring the edges in vertebrate sex determination. Curr. Opin. Genet. Dev. 18, 499-505 (2008).

5. Wilson, J. D., George, F. W. \& Griffin, J. E. The hormonal control of sexual development. Science 211, 1278-1284 (1981).

6. Wilhelm, D. \& Koopman, P. The makings of maleness: towards an integrated view of male sexual development. Nat. Rev. Genet. 7, 620-631 (2006).

7. Arboleda, V. A., Sandberg, D. E. \& Vilain, E. DSDs: genetics, underlying pathologies and psychosexual differentiation. Nat. Rev. Endocrinol. 10, 603-615 (2014).

8. Tanaka, S. S. \& Nishinakamura, R. Regulation of male sex determination: genital ridge formation and Sry activation in mice. Cell. Mol. Life Sci. 71, 4781-4802 (2014)

9. Harikae, K., Miura, K. \& Kanai, Y. Early gonadogenesis in mammals: significance of long and narrow gonadal structure. Dev. Dyn. 242, 330-338 (2013)

10. DeFalco, T. \& Capel, B. Gonad morphogenesis in vertebrates: divergent means to a convergent end. Annu. Rev. Cell Dev. Biol. 25, 457-482 (2009).

11. Chassot, A. A., Gillot, I. \& Chaboissier, M. C. R-spondin1, WNT4, and the CTNNB1 signaling pathway: strict control over ovarian differentiation. Reproduction 148, R97-R110 (2014).

12. Rodemer-Lenz, E. On cell contribution to gonadal soma formation in quail-chick chimeras during the indifferent stage of gonadal development. Anat. Embryol. (Berl). 179, 237-242 (1989).

13. Ariza, L., Carmona, R., Canete, A., Cano, E. \& Munoz-Chapuli, R. Coelomic epithelium-derived cells in visceral morphogenesis. Dev. Dyn. 245, 307-322 (2016).

14. Karl, J. \& Capel, B. Sertoli cells of the mouse testis originate from the coelomic epithelium. Dev. Biol. 203, 323-333 (1998).

15. Sekido, R. \& Lovell-Badge, R. Mechanisms of gonadal morphogenesis are not conserved between chick and mouse. Dev. Biol. 302, 132-142 (2007).

16. Hu, Y. C., Okumura, L. M. \& Page, D. C. Gata4 is required for formation of the genital ridge in mice. PLoS Genet. 9, e1003629 (2013).

17. Birk, O. S. et al. The LIM homeobox gene Lhx9 is essential for mouse gonad formation. Nature 403, 909-913 (2000).

18. Luo, X., Ikeda, Y. \& Parker, K. L. A cell-specific nuclear receptor is essential for adrenal and gonadal development and sexual differentiation. Cell 77, 481-490 (1994).
19. Stebler, J. et al. Primordial germ cell migration in the chick and mouse embryo: the role of the chemokine SDF-1/CXCL12. Dev. Biol. 272, 351-361 (2004).

20. Richardson, B. E. \& Lehmann, R. Mechanisms guiding primordial germ cell migration: strategies from different organisms. Nat. Rev. Mol. Cell Biol. 11, 37-49 (2010)

21. Barakat, M. T., Humke, E. W. \& Scott, M. P. Learning from Jekyll to control Hyde: Hedgehog signaling in development and cancer. Trends Mol. Med. 16, 337-348 (2010).

22. Jiang, J. \& Hui, C. C. Hedgehog signaling in development and cancer. Dev. Cell 15, 801-812 (2008).

23. Bandyopadhyay, A., Yadav, P. S. \& Prashar, P. BMP signaling in development and diseases: a pharmacological perspective. Biochem. Pharmacol. 85, 857-864 (2013).

24. Wharton, K. \& Derynck, R. TGFbeta family signalling: novel insights in development and disease. Development 136, 3691-3697 (2009).

25. Tonegawa, A., Funayama, N., Ueno, N. \& Takahashi, Y. Mesodermal subdivision along the mediolateral axis in chicken controlled by different concentrations of BMP-4. Development 124, 1975-1984 (1997).

26. Sukegawa, A. et al. The concentric structure of the developing gut is regulated by Sonic hedgehog derived from endodermal epithelium. Development 127, 1971-1980 (2000).

27. van den Brink, G. R. Hedgehog signaling in development and homeostasis of the gastrointestinal tract. Physiol. Rev. 87, 1343-1375 (2007).

28. Ayers, K. L., Smith, C. A. \& Lambeth, L. S. The molecular genetics of avian sex determination and its manipulation. Genesis 51, 325-336 (2013).

29. Yoshino, T., Saito, D., Tadokoro, R. \& Takahashi, Y. In vivo gene manipulations of epithelial cell sheets: a novel model to study epithelial-tomesenchymal transition. Dev. Growth Differ. 53, 378-388 (2011).

30. Hooper, J. E. \& Scott, M. P. Communicating with Hedgehogs. Nat. Rev. Mol. Cell Biol. 6, 306-317 (2005).

31. Narita, T., Ishii, Y., Nohno, T., Noji, S. \& Yasugi, S. Sonic hedgehog expression in developing chicken digestive organs is regulated by epithelial-mesenchymal interactions. Dev. Growth Differ. 40, 67-74 (1998).

32. Zhang, X. M., Ramalho-Santos, M. \& McMahon, A. P. Smoothened mutants reveal redundant roles for Shh and thh signaling including regulation of $\mathrm{L} / \mathrm{R}$ asymmetry by the mouse node. Cell 105, 781-792 (2001).

33. Marigo, V. \& Tabin, C. J. Regulation of patched by sonic hedgehog in the developing neural tube. Proc. Natl Acad. Sci. USA 93, 9346-9351 (1996).

34. Chuang, P. T. \& McMahon, A. P. Vertebrate Hedgehog signalling modulated by induction of a Hedgehog-binding protein. Nature 397, 617-621 (1999).

35. O’Hara, W. A., Azar, W. J., Behringer, R. R., Renfree, M. B. \& Pask, A. J. Desert hedgehog is a mammal-specific gene expressed during testicular and ovarian development in a marsupial. BMC Dev. Biol. 11, 72 (2011).

36. Madison, B. B. et al. Epithelial hedgehog signals pattern the intestinal crypt-villus axis. Development 132, 279-289 (2005).

37. Tsunekawa, N., Naito, M., Sakai, Y., Nishida, T. \& Noce, T. Isolation of chicken vasa homolog gene and tracing the origin of primordial germ cells. Development 127, 2741-2750 (2000).

38. Moustakas, A. \& Heldin, C. H. The regulation of TGFbeta signal transduction. Development 136, 3699-3714 (2009).

39. Shyer, A. E., Huycke, T. R., Lee, C., Mahadevan, L. \& Tabin, C. J. Bending gradients: how the intestinal stem cell gets its home. Cell 161, 569-580 (2015)

40. Saito, D., Takase, Y., Murai, H. \& Takahashi, Y. The dorsal aorta initiates a molecular cascade that instructs sympatho-adrenal specification. Science 336, 1578-1581 (2012).

41. Zimmerman, L. B., De Jesus-Escobar, J. M. \& Harland, R. M. The Spemann organizer signal noggin binds and inactivates bone morphogenetic protein 4 . Cell 86, 599-606 (1996).

42. Chiang, C. et al. Cyclopia and defective axial patterning in mice lacking Sonic hedgehog gene function. Nature 383, 407-413 (1996).

43. Hogan, B. L. Bone morphogenetic proteins in development. Curr. Opin. Genet Dev 6, 432-438 (1996).

44. Dudley, B., Palumbo, C., Nalepka, J. \& Molyneaux, K. BMP signaling controls formation of a primordial germ cell niche within the early genital ridges. Dev. Biol. 343, 84-93 (2010).

45. Wainwright, E. N., Svingen, T., Ng, E. T., Wicking, C. \& Koopman, P. Primary cilia function regulates the length of the embryonic trunk axis and urogenital field in mice. Dev. Biol. 395, 342-354 (2014).

\section{Acknowledgements}

Without the continued help of Dr Y. Takahashi, this paper would not have been possible. We are deeply grateful to Dr K. Hayashi, Dr K. Morohashi and Dr K. Agata. We also thank Dr K. Nakashima, Dr S. Katada, Dr T. Imamura, Dr Y. Sato, Dr T. Suzuki, Dr C. Tabin, Dr T. Ogura and Ms A. Uchiyama for helpful discussion and experimental materials. This work was supported by a Grant-in-Aid for Scientific Research from Japan Society for the Promotion of Science; the Mitsubishi Foundation; the Research Support Center; Research Center for Human Disease Modeling; Kyushu University Graduate School of Medical Sciences; and the Takeda Science Foundation. 


\section{Author contributions}

T.Y. and D.S. designed the study. T.Y., H.M. and D.S. performed the experiments. T.Y., H.M. and D.S. analysed the data. T.Y. and D.S. supervised the study. T.Y. wrote the manuscript.

\section{Additional information}

Supplementary Information accompanies this paper at http://www.nature.com/ naturecommunications

Competing financial interests: The authors declare no competing financial interests.

Reprints and permission information is available online at http://npg.nature.com/ reprintsandpermissions/
How to cite this article: Yoshino, T. et al. Hedgehog-BMP signalling establishes dorsoventral patterning in lateral plate mesoderm to trigger gonadogenesis in chicken embryos. Nat. Commun. 7:12561 doi: 10.1038/ncomms12561 (2016).

(c) (i) This work is licensed under a Creative Commons Attribution 4.0 International License. The images or other third party material in this article are included in the article's Creative Commons license, unless indicated otherwise in the credit line; if the material is not included under the Creative Commons license, users will need to obtain permission from the license holder to reproduce the material. To view a copy of this license, visit http://creativecommons.org/licenses/by/4.0/

(C) The Author(s) 2016 